\title{
DIGITALCOMMONS $@$ WAYNESTATE-

\section{Weight loss as sole treatment for obstructive sleep apnea in a patient with significant risks posed by daytime sleepiness}

Steven Daws

Wayne State University, gx7733@wayne.edu

Follow this and additional works at: https://digitalcommons.wayne.edu/crp

Part of the Medical Education Commons, and the Translational Medical Research Commons

\section{Recommended Citation}

DAWS S. Weight loss as sole treatment for obstructive sleep apnea in a patient with significant risks posed by daytime sleepiness. Clin. Res. Prac. Oct 13 2021;7(2):eP2649. https://doi.org/10.22237/crp/ 1625097960

This Clinical Decision Report is brought to you for free and open access by the Open Access Journals at DigitalCommons@WayneState. It has been accepted for inclusion in Clinical Research in Practice: The Journal of Team Hippocrates by an authorized editor of DigitalCommons@WayneState. 


\section{Weight loss as sole treatment for obstructive sleep apnea in a patient with significant risks posed by daytime sleepiness}

STEVEN DAWS, Wayne State University School of Medicine, gx7733@wayne.edu

\section{ABSTRACT A clinical decision report using:}

Kuna ST, Reboussin DM, Borradaile KE, Sanders MH, Millman RP, Zammit G, Newman AB, Wadden TA, Jakicic JM, Wing RR, Pi-Sunyer FX, Foster GD; Sleep AHEAD Research Group of the Look AHEAD Research Group. Long-term effect of weight loss on obstructive sleep apnea severity in obese patients with type 2 diabetes. Sleep. 2013 May 1;36(5):641-649A. https://doi.org/10.5665/sleep.2618

to inform whether weight loss alone can adequately and promptly treat OSA in a patient with high-risk employment and an aversion to more invasive intervention.

Keywords: $\quad$ weight loss, obstructive sleep apnea, treatment aversion

\section{Clinical-Social Context}

David Williams [pseudonym] is a 37 year-old African-American male presenting for evaluation in our Pulmonary \& Sleep Medicine clinic complaining of disturbed sleep. He reports episodes of loud snoring accompanied by gasping, choking and breathing cessation that have been witnessed by family members. His usual bedtime is between 2 AM and 3 AM, sleeping on average 6-7 hours each night. He wakes up feeling refreshed, but states he has significant daytime sleepiness, often requiring naps and often involuntarily dozing during sedentary activities such as reading or watching television. He reports three episodes of nocturia each night. He consistently wakes up with a dry mouth but denies any other morning symptoms. He denies any caffeine or other stimulant use. The presumptive new diagnosis is obstructive sleep apnea (OSA).

Mr. Williams past medical history includes type II diabetes mellitus, Fournier gangrene, multiple cutaneous abscesses requiring surgical drainage, pulmonary hypertension, peptic ulcer disease, asthma and morbid obesity. His most recent $\mathrm{HgA1c}$ was $15.8 \%$, his current $\mathrm{BMI}$ is $56.7 \mathrm{~kg} / \mathrm{m} 2$ and his blood pressure on encounter is $158 / 99$ $\mathrm{mmHg}$. Recent arterial blood gas readings indicate chronic hypercapnia. Physical examination demonstrates a neck collar size of 17 inches, a low hanging palate, a narrow and foreshortened pharynx, 3+ tonsils bilaterally and a relatively massive uvula. His home medications include furosemide, albuterol and subcutaneous insulin with no reported difficulties regarding adherence. He has a twenty pack-year history of tobacco use, though has recently reduced to one pack per week as part of a larger effort to improve the trajectory of his overall health. He smokes multiple marijuana blunts daily and consumes alcohol sparingly.

STEVEN DAWS is a student at the Wayne State University School of Medicine. 
DAWS S. Weight loss as sole treatment for obstructive sleep apnea in a patient with significant risks posed by daytime sleepiness. Clin. Res. Prac. Oct 13 2021;7(2):eP2649.

https://doi.org/10.22237/crp/1625097960
Clinical Research in Practice The Journal of Team Hippocrates

VOL 7 ISS 2 / eP2649 / OCTOBER 13, 2021 https://doi.org/10.22237/crp/1625097960

During a past episode of ventilator-dependent respiratory failure, the patient required a stay in a long term acute care facility and underwent tracheostomy, which remained in place for 30 months. Decannulation took place approximately three months prior to presenting to our clinic, but a small residual hole remains that will likely require future repair. The patient spoke very negatively about his experiences living with a stoma, and he was decannulated at his request once his frustrations grew intolerable. He mentioned feelings of embarrassment and anxiety when noticing people's attention constantly being drawn towards it. Mr. Williams is single and desires a relationship but found his tracheostomy to be a barrier to intimacy.

Daytime sleepiness poses an immediate major health risk for this patient. He is employed as an industrial forklift driver at an auto plant, and regularly operates multiple forms of heavy machinery during long shifts. Therefore relatively expedient management of his OSA would be ideal. Drawing on his tracheostomy experience, Mr. Williams is reluctant to undergo any surgical intervention such as repeat tracheostomy, bariatric surgery, or uvulopalatopharyngoplasty. He is open to trialing continuous positive airway pressure (CPAP) but foresees difficulty in adherence as he often sleeps in different locations and worries it may affect his romantic relationships. Some consideration was given to use of a mandibular advancement appliance, but the patient expressed a desire for a curative therapy, as opposed to one requiring continued lifelong management and adherence. Mr. Williams reports a weight loss of more than 200 pounds over the last year as a result of exercise and diet modification, currently weighing 430 pounds. He wants to know if continued weight loss will cure his OSA.

\section{Clinical Question}

How effective is weight loss alone in treating obstructive sleep apnea in a patient with multiple comorbidities?

\section{Research Article}

Kuna ST, Reboussin DM, Borradaile KE, Sanders MH, Millman RP, Zammit G, Newman AB, Wadden TA, Jakicic JM, Wing RR, Pi-Sunyer FX, Foster GD; Sleep AHEAD Research Group of the Look AHEAD Research Group. Long-term effect of weight loss on obstructive sleep apnea severity in obese patients with type 2 diabetes. Sleep. 2013 May 1;36(5):641-649A. https://doi.org/10.5665/sleep.2618 $\underline{1}$

\section{Description of Related Literature}

A review of literature was performed beginning with a PubMed search for the MeSH terms "behavior therapy," "weight loss," "obstructive sleep apnea," and "treatment outcomes" which yielded 19 results. Seeking high level evidence, the results were filtered to include only randomized controlled trials, systematic reviews and meta-analyses, giving 9 articles. On review of the abstracts for those 9 articles, only 7 were deemed relevant to the clinical question -5 controlled trials and 2 systematic reviews.

Foster et al. $\stackrel{2}{ }$ and Kuna et al. $\stackrel{1}{ }$, documented the same controlled trial, with the Kuna et al. article being a successive report documenting the same group of patients after a longer follow up period but including the data presented by Foster et al. In so far as the one report is essentially contained in the other, Kuna et al. offers the relatively more valuable study. It presents the results of a randomized trial held at four clinical centers that included 264 patients with a diagnosis of OSA and comorbid type 2 diabetes. Its control group received standard diabetes support and education, while its experimental arm received an intensive weight loss intervention. Follow up was performed at 1, 2 and 4 years, with the primary end point being apnea-hypopnea index (AHI), and showed greater sustained improvement in the experimental group. Ultimately, the Kuna et al. study was deemed to be of superior value to the other three clinical trials in answering the clinical question posed by Mr. William's case, and was therefore chosen for clinical appraisal.

$\mathrm{Ng}$ et al. $\underline{3}$ conducted a randomized controlled trial involving 104 patients with obesity and OSA that evaluated the effect of dieticianled lifestyle modifications after one year. Primary end points of the study were Apnea-Hypopnea Index (AHI), Epworth Sleepiness Scale and Short Form Health Survey, and improvement was seen in all three parameters. However, this study was a superiority study, with the patients in both arms of the trial also using continuous positive airway pressure (CPAP) if they elected to - an 
DAWS S. Weight loss as sole treatment for obstructive sleep apnea in a patient with significant risks posed by daytime sleepiness. Clin. Res. Prac. Oct 13 2021;7(2):eP2649.

https://doi.org/10.22237/crp/1625097960
Clinical Research in Practice The Journal of Team Hippocrates

VOL 7 ISS 2 / eP2649 / OCTOBER 13, 2021 https://doi.org/10.22237/crp/1625097960

intervention Mr. Williams has some reservations towards. Additionally, the Kuna et al. trial was much higher powered and had a much longer duration of follow up.

Tuomilehto et al. $\stackrel{4}{ }$ conducted a randomized controlled trial involving 72 patients with obesity and OSA that evaluated the effect of a twelve-week, very low calorie diet on AHI and 15D-Quality of Life scores, the latter being a generic standardized measure of healthcare related quality of life. The authors ultimately reporting improvement in both parameters. While this study is indeed relevant to Mr. William's case, similar to the study by $\mathrm{Ng}$ et al., it is inferior with regard to power and duration compared to the Kuna et al. trial.

Shechter et al. $\underline{5}$ conducted a randomized controlled trial involving 264 patients with obesity, type 2 diabetes and OSA that evaluated the effect of an intensive weight loss intervention on sleep architecture over four years. This study is comparable to the Kuna et al. study in power and duration. In Mr. Williams clinical scenario, he presents with uncontrolled diabetes that will be treated concurrently regardless of which modality is chosen to treat his OSA, making both the Kuna et al. and Schechter et al. studies particularly applicable in this regard. However, the metric employed by Kuna et al. - AHI - is more clinically relevant than the metric employed by Shechter et al. - sleep architecture.

A repeat PubMed query using the search terms "obstructive sleep apnea AND treatment AND weight loss only" was performed and it revealed three additional potential articles which were also reviewed. Chirinos et al. $\underline{6}$ conducted a randomized trial examining the relationship between OSA and inflammation, insulin resistance, dyslipidemia and hypertension, which included a weight loss intervention arm. Because it did not include any primary metrics of OSA its evidence is an additional degree removed from the clinical question. Truby et al. ${ }^{-}$conducted a randomized trial investigating the role of a weight loss intervention on weight trajectory for individuals also using CPAP therapy. Because Mr. Williams is unwilling to use CPAP, the findings of this study are not particularly relevant to his case. Lam et al. ${ }^{8}$ completed a randomized study of three non-surgical treatments - sleep hygiene, CPAP and oral appliance - in 101 patients with mild to moderate OSA. Within those three treatment arms, anyone who was overweight was also referred for a weight-reduction class. The study ultimately found CPAP to have the greatest effect on physiologic and symptomatic measures of OSA, with oral appliances also being effective. Weight loss was found to correlate strongly with reduction in AHI. This study was not as highly powered as the Kuna et al. study and the fact that weight loss was used in conjunction with other treatments limits its relevance to Mr. Williams desired treatment course. It also fails to take into account relevant comorbidities, namely diabetes. The study also found only about $10 \%$ of patients achieved an $\mathrm{AHI}<5$ from weight loss alone, which in general does contradict the findings of the studies herein discussed. However, for a disease of multifactorial etiology like OSA, complete resolution is a less useful outcome measure, as an intervention is likely to be only treating one underlying cause. Additionally, because the study found a linear relationship between $\mathrm{AHI}$ and weight loss, it is simply possible patients did not lose enough weight, especially considering the intervention was only in place for the brief period of 10 weeks.

The two meta-analyses by Edwards et al. $\underline{9}$ and Araghi et al. $\underline{10}$ are not in opposition to the conclusions of Kuna et al., instead supporting the notion that weight loss is an inexpensive, effective and efficient treatment for OSA. The expansive inclusion criteria found in both meta-analyses, however, render them less applicable to the clinical circumstances presented by Mr. Williams. As a final step to ensure the selection of the most appropriate article to address the clinical question, the Kuna et al. article was found within Google Scholar and the "related articles" function was used to determine no relevant studies were missed.

Using the SORT criteria, $\underline{\underline{11}}$ The Grade of Recommendation for weight loss as a single treatment option for Obstructive Sleep Apnea is A based on ten studies, including eight controlled trials and two systematic reviews.

\section{Critical Appraisal}

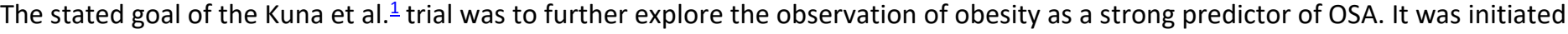
under the auspices of Sleep AHEAD (Action for Health in Diabetes), which was an ancillary investigation of Look AHEAD which merely sought to evaluate the effect of an intensive lifestyle modification on diabetes and associated cardiovascular disease. The study was a randomized controlled trial. Inclusion criteria from the Look AHEAD study were age 45-76, BMI less than $25 \mathrm{~kg} / \mathrm{m} 2 \mathrm{or}$ if taking insulin less than $27 \mathrm{~kg} / \mathrm{m} 2$, physician-verified type 2 diabetes, HgA1c less than $11 \%$ and blood pressure less $160 / 100 \mathrm{mmHg}$. Previous OSA treatment was the primary exclusion criteria. Participants were then randomized via computer, with the randomization being stratified by the four involved clinical centers and blocked with random block sizes. One group participated in a group behavioral 
DAWS S. Weight loss as sole treatment for obstructive sleep apnea in a patient with significant risks posed by daytime sleepiness. Clin. Res. Prac. Oct 13 2021;7(2):eP2649.

https://doi.org/10.22237/crp/1625097960
Clinical Research in Practice The Journal of Team Hippocrates

VOL 7 ISS 2 / eP2649 / OCTOBER 13, 2021 https://doi.org/10.22237/crp/1625097960

weight loss program particularly catered to obese patients with type 2 diabetes, which included liquid meal replacements, snack bars and physical activity requirement for the first year. For the second, third and fourth years intervention was provided on an individual basis. The other group underwent a support and education program in which behavioral strategies were not presented, but diet and physical activity were generally discussed. Prior to initiation of the program, all participants underwent baseline polysomnography and morphometric testing, which resulted in the exclusion of 41 patient due to an observed AHI of less than 6 .

Strengths of this study include its randomization, blinding, and power. The previously mentioned randomization process was indeed adequate in its design and subsequently validated with no significant differences found in demographics, physical characteristics and baseline disease state. The personnel collecting outcomes measures, technologists performing the sleep studies, and the biostatisticians collecting data were all blinded throughout the trial. With 264 participants, the study was adequately powered to generate clinically valuable predictive measures.

The are several notable weaknesses in the design and execution of the Kuna et al. trial. The first is that the participants were not recruited directly and exclusively for the study, but rather were recruited as an ancillary study to the Look AHEAD program. Not only does this process preselect for a highly motivated patient population, thereby introducing undue participation bias, but also attrition rates and compliance could be altered by the concurrently measured outcomes for the Look AHEAD study. Indeed a significant attrition rate of $37.5 \%$ was observed. This attrition may also have been due to the intervention itself which is - by its own descriptor - intense, which also additionally limits the intervention's feasibility in practice. An additional weakness was the dramatic change in intervention after 1 year, after which the intervention was provided on an "individual basis," amounting to a reduction in standardization. There are also weaknesses inherent in some of the metrics used, especially AHI which is known to vary considerably for each individual on a night-to-night basis. This is of particular concern regarding the exclusion of the individuals with an $\mathrm{AHI}<6$ on baseline testing as a number of mild OSA cases may have been dismissed.

Overall, as a prospective, controlled clinical trial the Kuna et al. study embodies a relatively high standard of evidence. While several potential conflicts of interest were reported by the authors, none were so worrisome as to call into question the validity of the data. Within the Strength of Recommendation Taxonomy (SORT), the Kuna et al. trial would be classified as Level 2 evidence. $\underline{\underline{11}}$

\section{Clinical Application}

The Kuna et al. trial has good external validity within the clinical context presented by Mr. Williams. With the exception of $\mathrm{HgAlc}$, he meets all of the study's inclusion criteria. It is worth noting however that Mr. Williams' age and $\mathrm{BMI}$ are quite removed from the mean of the study population: 37 years versus 61.3 , and $56.7 \mathrm{~kg} / \mathrm{m} 2$ versus 36.6. As previously discussed, Mr. Williams will necessarily be receiving treatment for type 2 diabetes regardless of the chosen management for his OSA. Therefore, the fact that both the experimental and control arms consisted of individuals receiving treatment for diabetes greatly enhanced the applicability of the Kuna et al trial.

Mr. Williams ultimately wishes for his OSA to be managed as conservatively as possible, and already has good momentum towards substantial weight loss. He is highly motivated as he as certain unmet desires, namely his wish for a romantic relationship and an increased feeling of normalcy that could be hindered by invasive apparatuses, whether it be CPAP or a tracheostomy tube. The general conclusion of the Kuna et al. trial would indicate that there is a high probability that his OSA could indeed be effectively treated with weight loss, which is a finding consistent with those in the related literature. However, Mr. William's employment as an operator of heavy machinery adds an additional important parameter. His unique clinical context demands that his OSA not only be treated effectively, but also promptly. The Kuna et al. trial estimated a $.43 \mathrm{AHI}$ reduction per kilogram of weight loss. The question then becomes how quickly Mr. Williams is able to lose weight, and from what baseline AHI he is starting? He will be promptly referred for a sleep study to answer the latter question. If he continues to experience on-the-job sleepiness he is willing to consider CPAP during the interim period as he continues to lose weight, in the hope that he will soon be able to transition to his ideal lifestyle and self-image. The findings of the Kuna et al. trial support that notion as a viable possibility, and an appropriate course of action. 


\section{New Knowledge Related to Clinical Decision Science}

Mr. Williams, like all patients, presented with his unique set of desires, motivations and preferences. In this case, he has multiple serious medical problems, but his management focused on something that was important to him. His social circumstances demanded the inclusion of timeliness as a parameter when choosing a treatment modality for his OSA. Another issue with the decision making is whether Mr. Williams could or would accept multiple simultaneous treatments. Evaluating mouth devises for OSA versus CPAP should be re-visited on multiple visits because of the complexity of his social circumstances and his medical comorbidities.

Clinical research often focuses simply on whether an intervention is associated with a particular outcome, but not necessarily the timeframe over which that outcome manifests. As Mr. Williams' case demonstrates, the need for prompt or delayed management is often determined by a patient's social history and is thereby an important component of any clinical decision-making process.

\section{Conflict Of Interest Statement}

The author declares no conflicts of interest.

\section{References}

1. Kuna ST, Reboussin DM, Borradaile KE, et al. Long-term effect of weight loss on obstructive sleep apnea severity in obese patients with type 2 diabetes. Sleep. 2013;36(5):641-649A. https://doi.org/10.5665/sleep.2618

2. Foster GD, Borradaile KE, Sanders $\mathrm{MH}$, et al. A randomized study on the effect of weight loss on obstructive sleep apnea among obese patients with type 2 diabetes: the Sleep AHEAD study. Arch Intern Med. 2009;169(17):1619-1626. https://doi.org/10.1001/archinternmed.2009.266

3. Ng SSS, Chan RSM, Woo J, et al. A Randomized Controlled Study to Examine the Effect of a Lifestyle Modification Program in OSA. Chest. 2015;148(5):1193-1203. https://doi.org/10.1378/chest.14-3016

4. Tuomilehto HP, Seppä JM, Partinen MM, et al. Lifestyle intervention with weight reduction: first-line treatment in mild obstructive sleep apnea. Am J Respir Crit Care Med. 2009;179(4):320-327. https://doi.org/10.1164/rccm.200805-6690C

5. Shechter A, St-Onge MP, Kuna ST, et al. Sleep architecture following a weight loss intervention in overweight and obese patients with obstructive sleep apnea and type 2 diabetes: relationship to apnea-hypopnea index. J Clin Sleep Med. 2014;10(11):12051211. Published 2014 Nov 15. https://doi.org/10.5664/jcsm.4202

6. Chirinos JA, Gurubhagavatula I, Teff K, et al. CPAP, weight loss, or both for obstructive sleep apnea. N Engl J Med. 2014;370(24):2265-2275. https://doi.org/10.1056/NEJMoa1306187

7. Truby H, Edwards BA, O'Driscoll DM, et al. Sleeping Well Trial: Increasing the effectiveness of treatment with continuous positive airway pressure using a weight management program in overweight adults with obstructive sleep apnoea-A stepped wedge randomised trial protocol. Nutr Diet. 2019;76(1):110-117. https://doi.org/10.1111/1747-0080.12435

8. Lam B, Sam K, Mok WY, et al. Randomised study of three non-surgical treatments in mild to moderate obstructive sleep apnoea. Thorax. 2007;62(4):354-359. https://doi.org/10.1136/thx.2006.063644

9. Edwards BA, Bristow C, O'Driscoll DM, et al. Assessing the impact of diet, exercise and the combination of the two as a treatment for OSA: A systematic review and meta-analysis. Respirology. 2019;24(8):740-751. https://doi.org/10.1111/resp.13580

10. Araghi MH, Chen YF, Jagielski A, et al. Effectiveness of lifestyle interventions on obstructive sleep apnea (OSA): systematic review and meta-analysis. Sleep. 2013;36(10):1553-1562E. https://doi.org/10.5665/sleep.3056

11. Ebell MH, Siwek J, Weiss BD, et al. Strength of recommendation taxonomy (SORT): a patient-centered approach to grading evidence in the medical literature. J Am Board Fam Med. 2004;12(1):59-67. https://doi.org/10.3122/jabfm.17.1.59 